\title{
MISREPRESENTING NURSES: AN OVERVIEW OF SOME SELECTED NOLLYWOOD MOVIES
}

\section{Aduragbemi Oluwapelumi Ogunleye}

\author{
Department of Nursing Science. University of Ibadan, Ibadan, Nigeria
}

Cite this article:

Aduragbemi Oluwapelumi

Ogunleye (2021),

Misrepresenting Nurses:

An Overview of Some

Selected Nollywood

Movies. African Journal of

Health, Nursing and

Midwifery, 85-93. DOI:

10.52589/ajhnm_XCW1WI AR.

https://abjournals.org/ajhn $\mathrm{m} /$ papers/volume-4/issue$1 /$ misrepresenting-nursesan-overview-of-someselected-nollywoodmovies/

\section{DOI: 10.52589/} ajhnm_XCW1WIAR

Received: 17 February 2021

Accepted: 18 March 2021

Published: 18 April 2021

Copyright $($ C 2020 The Author(s). This is an Open Access article distributed under the terms of Creative Commons AttributionNonCommercialNoDerivatives 4.0 International (CC BY-NC-ND 4.0 ), which permits anyone to share, use, reproduce and redistribute in any medium, provided the original author and source are credited.
ABSTRACT: The projected image of any profession is a determining factor of the level of respect that would be accorded to the services rendered by members of such profession. In the same vein, this image would build confidence which people will repose in the operators of such services. Nursing, a popularly acclaimed noble profession, has enjoyed the wider acceptability of the Nigerian populace from time immemorial. Nurses are lifesavers; this, therefore, accorded them the opportunity to occupy the enviable position they are holding today in Nigeria. However, as projected by the Nigerian Nollywood actors and actress, the image of nurses and nursing profession has been that of misrepresentation, which has exposed Nurses to an unwarranted embarrassment in their bid to create an atmosphere of entertainment. Consequently, this misrepresentation sends the populace the wrong signal about the nursing career and the enviable position that nurses occupied in society. Therefore, the paper aims to review some selected Nollywood movies that portrayed nurses' image in a wrong perspective. It will also present the true image of Nigerian nurses, both at home and abroad. The paper employs qualitative sources of data collection, which comprises: observations, printed documents, downloaded videos and internet materials. The paper concludes that nursing is an invaluable and noble profession that should be presented as such. The paper recommends that nurses themselves should jealously guard nursing profession, the Film Censor's Board in Nigeria should intensify efforts in movie censoring before the final release of movies and the actors should desist from presenting nurses in a wrong perspective to checkmate the temptation of sending misconceived ideas about the Nigerian Nurses to the public.

KEYWORDS: Nollywood, Misrepresentation, Image, Nursing profession, Public 


\section{INTRODUCTION}

Over the years, the nursing profession has been responding to Nigerian society's dynamic healthcare needs. Consequently, her professional ethos remained intact in her bid to establish professionalism. This, therefore, made the nursing profession to be compared to a magnet that pulls patients' healthcare needs together (American Nurses Association, 2020). In this regard, nurses, who are the pillars and ambassadors of the nursing profession have been highly reverenced from the days of yore. The reason for this is not farfetched, as the roles that nurses play in attending to the healthcare needs of patients in their care cannot be over-emphasized. Their roles include assessing patients, medication administration, monitoring of patient's health, provision of support and advice to patients and their families, and health education, amongst others have made it convincing that nurses are indispensable in the health care system.

The Nigerian film industry, fondly called Nollywood, ranked as the world's second-largest movie producing industry in terms of volume, has created and is still creating entertainment for Nigerians and beyond (Guardian, 2019). However, it has been observed that Nollywood's presentation of nurses in most of its movies is not in conformity with the true image of professional nurses. Sequel to this, wrong signals are being sent to the public about the Nigerian nurses' image and the functions they perform. Therefore, it is the attempt to prevent the handover of a baton of the distorted image to the upcoming generation of nurses and correct the wrong impression about nurses in this generation that prompted this research response.

\section{Aim}

This study aims at addressing the wrong portrayals of nurses in Nollywood movies, discuss the effects of the menace, present the actual image of nurses and recommend ways to forestall further misrepresentation of nurses.

\section{Methodology}

The study employed a qualitative approach of data collection to review Nollywood movies that misrepresented nurses. Sources of data collectees-comprise observations, printed documents, downloaded videos and internet materials.

\section{Review of Some Selected Movies and Effects of their Misrepresentation}

Research has shown that health-related movies can function as a vehicle that motivates its audience to make better decisions about their health (National Academy of Sciences, 2015). This fact cannot be disputed as such movies have been observed to stress the importance of medical check-ups and create medical awareness of diverse health issues. Various medical and health-related movies by Nollywood producers and directors have been and still in circulation in the entertainment industry. Some of these movies have correctly created awareness to Nigerians about living a healthy life, including the dangers of not doing so. However, some other movies have been observed to function contrary to creating awareness and portraying health workers, especially professional nurses, in good light. Professional nurses who are licensed health workers that work their hands to the bone in service for humanity have been portrayed in misrepresented characters in most Nollywood health-related movies. Portrayals of nurses as gracers of physicians' and patients' bed in clinics and as gossips while on duty, to mention a few, have become the order of the day on most screens of viewers. The consequences of these bad representations are enormous. It has been observed that some of the movies' 
storylines were often tailored towards destroying the public's perception about nurses and the nursing profession. Apart from this, various unfounded theories have been fabricated around the profession. Theories such as: nurses can only work in hospitals, nurses are only women, nurses are not as intelligent as doctors, and many more are being carried around (Nielson, 2012). In this regard, some Nollywood movies where nurses were inappropriately portrayed have been randomly selected for critical review.

\section{Heartless Nurse (2015)}

The first movie to be premiered for review in this article is titled: Heartless Nurse. Onyeka Joe Orajiaka produced it in the year 2015. The movie portrayed a matron who lacked empathy for patients brought to the hospital. She was also portrayed as lacking collegiality while consequently belittling other nurses that are subordinate to her. This was evident in her manner of approach to patients and her colleagues at work.

To infer that this misplaced depiction of nurses, painted in the movie, will surely affect nurses, healthcare institutions, and the public is not an overstatement. Nurses are on the receiving end as it paints them as cruel, wicked, apathetic, unapproachable and nasty individuals who have no value for human life. This therefore, has defeated the popular claim that nurses are the 'heartbeat of healthcare' because of their involvement in the healthcare journey of individuals, family and communities. It likewise goes contrary to the description of nurses as 'gatekeepers to life at birth and death' (Adejumo, 2018). If vital workers in healthcare institutions are being painted negatively, the fact that the healthcare institutions will also suffer this negativity cannot be disputed. In this regard, healthcare institutions become a place that scares patients as the confidence reposed in its ability to attend to the public's healthcare needs through its workers is in doubt. In the long run, members of the public who need medical attention will see it inappropriate to visit healthcare institutions.

When this happens, there might consequently be a rise in the public's mortality rate as there is a gap in healthcare intervention to be filled by health workers. Moreover, the public also suffers setback in a potential career in nursing because of erroneous representation. The reason for this is not farfetched, as depictions in media can influence career choices (Escobar \& Heilemann, 2019). No one would want to opt for a health-related career that maltreats patients as shown on their screens, thereby leaving the public in ignorance of the profession's true image.

\section{Sisi Nurse (Nursing Sister) (2016)}

The next movie to be reviewed, titled Sisi Nurse (Nursing Sister), was produced in the year 2016 by Bukola Abiola. Nurses were erroneously portrayed as fetish health workers who rob patients of their lives in exchange for money. This was corroborated in some of its scenes where a nurse character used fetish material to kill patients in her desperate search for money.

It should be noted that people are influenced by what they see, and in a similar vein, movies can influence its audiences' beliefs and opinions on various issues (Kubrak, 2020). Therefore, it is, safe to admit that this erroneous portrayal might have an adverse effect on people's opinions and beliefs about nurses, which is likely to linger for long in their minds. From what has been discussed above, one may be tempted to think that this erroneous representation of nurses by Nollywood actors may generate public hatred towards nurses and their profession if Nollywood movies are not adequately censored. It is possible for an individual, family or community who has watched movies that depicted nurses wrongly not to allow nurses attend 
to them when in need of their services. The negative perception of the public about nurses, if not addressed, may transform nurses from being angels of healthcare to devils with the syringe.

\section{Abiyamo (2017)}

Another Nollywood movie that depicts an inappropriate representation of nurses is a movie titled 'Abiyamo' (Motherhood). The movie was produced in the year 2017 by Ronke Ojo, had its settings based in the Yoruba land of Nigeria. It erroneously presented nurses as gossipmongers in one of its scenes where two nurses were seen chit-chatting at the patient's expense in their care, thereby neglecting their duties.

Dismally, this erroneous portrayal of nurses has been found to have a backwash on the nursing profession. It belittles the enviable position that nurses and the nursing profession have occupied in healthcare systems. Nurses' functions in the healthcare journey of individuals, families, and the community from time immemorial have placed the nursing profession in a covetable position of professionalism in healthcare. Likewise, WHO (2010) concurred to this fact in one of her works which were cited by Ubochi et al (2019), where the nursing workforce was identified as an invaluable tool for healthcare transformation.

Therefore, the ill-representation of nurses as gossipmongers and workers who neglect their duties demands urgent attention to prevent the weights of misrepresentation from pulling down the cords that hold the profession in position.

A recent occurrence at the Federal Medical Centre, Owo, Ondo State in Nigeria, as reported by This Day Newspaper (2021), reports the assault on three nurses by the relatives of a suspected COVID-19 patient who died in the hospital. This, no doubt, is an effect of the erroneous portrayal of nurses in movies. The belief that nurses' bad portrayals have created in the minds of the public about nurses made the relatives concluded that the nurses were not up to par in discharging their duties, thereby resulting in assault. News source has it that the relatives blamed the nurses' 'carefree attitude' for death. However, in defence, the nurses' chairman in the hospital claimed that the nurses and doctors tried their best.

\section{Nurses Club (2013)}

The next in the continuum is titled Nurses' Club which was produced in the year 2013 and directed by Ikenna Irikannu. This movie was tailored towards portraying nurses as sex objects in the hands of doctors and their patients while on duty. Nurses were portrayed as professionals who never missed the opportunity of having carnal knowledge of their patients and of the doctor who just got posted to the hospital in exchange for money. The drama rendered an overstated misrepresentation of Nigerian nurses in its scenes through its characters that were grossly obsessed with sex. Moreover, the drama's characterisation reflected nurses who were always in tight-fitted, thigh revealing white uniforms with a front slit in the thigh region and a front zipper in the chest region that was open most of the time. Coupled with this is the flirtatious look in their eyes when addressing patients.

The implication of this exaggerated misrepresentation of nurses as sex workers in contrast to their work as lifesavers is that it beclouds the interest of the public in nurses. This implies that the respect that the general public has for the nursing profession will go down the plughole. This consequential fact was confirmed by a Nigerian registered nurse who narrated her experience about the public's perspective about nurses as people who sleep with doctors. (Ajah, 
2018). Besides, the dress code of the characters who imitated nurses in the movie runs contrary to nursing's dressing ethics as it in no way depicts nurses. Nurses' uniforms affect the image of nursing practice and the nursing profession (Wocial et al., 2014). This claim agrees to that of West et al. (2016) that a uniform is a mirror the public uses to identify the wearer's role. By and large, the logical consequence of this erroneous representation is not only that it may stain the garment of the nursing profession, but it is also an attempt to tarnish the image of nurses.

\section{Agbanilagbatan (2020)}

Last but not least among the review of some selected Nollywood movies that have inappropriately represented nurses is the review of the movie titled 'Agbanilagbatan'; A Yoruba Nollywood movie which was produced in the year 2020. This paper is reacting to one of the scenes in the movie, where an actress who acted the role of a nurse-midwife was actively aiding and abetting in the sale of a newborn baby to a woman who was not the mother. The movie erroneously portrayed nurse-midwives as healthcare workers who indulge in criminal activities. With reference to the professional ethics of midwifery, this scene runs contrary to the scope of practice of midwives as stated by the International Confederation of Midwives (ICM, 2018) cited by Pairman and Tumilty (2016) that:

The midwife is recognized as a responsible and accountable professional who works in partnership with women to give the necessary support, care and advice during pregnancy, labour and the postpartum period to conduct births on the midwife's responsibility and to provide care for the newborn and the infant. This care includes preventative measures, the promotion of normal delivery, the detection of complications in mother and child, accessing medical care or other appropriate assistance, and carrying out emergency measures.

Admittedly, to state that nurse-midwives and nurses generally may suffer a loss of their occupational pride due to this misrepresentation is not an overstatement. This becomes evident when nurse-midwives can no longer stand tall to boast about their profession and gallantly utilise their professional skills when discharging their duties.

\section{Nurses in True Perspective}

The aim of this paper is not only to address the corrupted image of nurses as portrayed in the reviewed Nollywood movies, but it is also interested in bringing to limelight the true picture and perspective of professional nurses that might have been misconstrued in the minds of the populace by the media.

The effort to portray the true image or characteristics of professional nurses would be fruitless if we fail to reflect on nurses' functions. To accurately determine this, it is important to go down the memory lane to examine the roles played by Florence Nightingale, the founder of modern nursing, during the Crimean war, which made her famous. She was involved in the promotion of well-being of the wounded soldiers during the Crimean War in the $19^{\text {th }}$ century. This indicates that nursing involves taking the responsibility of promoting people's health (Shetty, 2016). This thereby clearly shows one of the significant functions that nurses perform.

Moreover, Virginia Henderson, the quintessential nurse of the $20^{\text {th }}$ century (Wikipedia, 2020), highlighted nurses' unique functions in her publication. She said inter-alia that nurses: 
'assist the individual, sick or well, in the performance of those activities contributing to health or its recovery(or to peaceful death) that he would perform unaided if he had the necessary strength, will or knowledge' (Henderson, 1966 ).

Having recognised that the functions of professional nurses are vital to life, the actual image or characteristics of professional nurses are thereby tailored towards saving lives. It can therefore be unarguably said that nurses are equipped with professional values of altruism, autonomy, human dignity, integrity and social justice (Chikeme et al., 2019). It should also be noted that experienced nurses are humane, caring and are not subordinate to doctors in any form (Adejumo, 2018). They do not grace their patients' and doctors' beds with their bodies for any gratification whatsoever. There are both males and females in the nursing profession. Professional nurses are likewise brilliant and intelligent as they excel in their various areas of specialisation.

\section{Ways out of Media Misrepresentation of Nurses}

It is no longer news that the adverse effects of media misrepresentation of nurses is taking its toll on the nursing profession in recent years. This indicates that if misrepresentation is not nipped in the bud, it may lead to professional assassination and loss of the true identity of nurses. The attempt to create an urgent awareness on the proper perspective about the Nigerian nurses makes it paramount for this study to suggest ways of removing media misrepresentation of nurses in Nigeria.

First among the major ways of addressing media misrepresentation of nurses is for nurses to intensify their efforts on public enlightenment campaigns against the dissemination and production of such erroneous works by film producers in Nigeria. All professional nurses in Nigeria, whether practicing or non-practising should come together to carry out this noble course. The general public should be sensitized so as to know the accurate picture of Nigerian nurses. They should make it known to the public the need for nurses in healthcare, their roles, and their healthcare journey. This campaign can be done through many social media platforms such as Twitter, Instagram, Facebook, WhatsApp etc. It can also be executed via radio and television.

Nigerian nurses' recent reaction to the erroneous representation of nurses in a musical video released online by a popular Nigerian artiste, Olamide, in his song titled: Wonma, indicated that nurses have been responding to the clarion call to guard the nursing profession jealously. The video that portrayed nurses as sexual objects, was eventually withdrawn from circulation after a series of criticism from nurses and public members under the hashtag \#NursesAreNotSexualObjects\#. (Lailas News, 2020).

Secondly, various nursing professional bodies in Nigeria should maintain their stance in protecting the profession against the use of derogatory terms through media misrepresentation. The bodies should also involve government agencies to take proper action when necessary.

Thirdly, film producers and actors must be guided by the ethics of their profession. They should guide against character and professional assassination. Producers should carry out proper and elaborate research on their work before the final production. Therefore, the onus lies on the producers of Nollywood videos to embark on thorough research on the ethics and principles guiding the nursing profession and other professions to prevent misconceptions. This claim 
was supported by Paul Obazele, the president of the film producers association of Nigeria, in 2010, during a meeting with the Nursing and Midwifery Council of Nigeria (NMCN) on nurses' portrayal in Nigerian movies. He suggested that conferences and workshops be organised for movie producers to educate and make them conversant with the acceptable standards of nursing practice by professional nursing bodies in Nigeria. (Nursing World Nigeria, 2012)

Also, Nollywood actors should give 'character building' or 'getting into character' a top priority whenever they want to feature in movies as nurses characters. Character building involves carrying out intricate research about the character to be imitated and bringing the scripted character to life (Cannon \&Gardner, 2009). This should be seen by Nollywood actors as a tool for professional development in their careers and to be viewed as a major criterion for imitating nurses in movies. This can be best implemented through a series of consultations and interviews with nurses and nursing bodies.

Furthermore, nurses' erroneous media representation can be curtailed by nurses themselves when they imbibe professional values and cultivate the right attitude to work. This is because nurses' attitude or behaviour when carrying out their professional duties and interprofessional collaboration is regularly observed by patients and other health professionals. Subsequently, impressions, which are either good or bad, are formed from the observations (Oyetunde et al., 2014), determining the public's perception of nurses. Hence, a positive attitude to work is synonymous with positive perception and representation of nurses.

It should be noted that when professional nurses are equipped with professional values, it will determine their attitude to work. Lai and Lim (2012), cited by Poorchangizi et al., (2017), recognised that values serve as principles and motivation for professional behaviour. A literature review on Nursing Ethical Values and Definitions by Shahriari et al., (2013), highlighted nursing ethical values that nurses should be equipped with. These include human dignity, altruism, social justice, autonomy in decision making, precision and accuracy in caring, responsibility, human relation, individual and professional competency, sympathy and trust.

In addition, the intensified efforts of the National Film and Videos Censors Board (NFVCB) in the censorship of movies produced in Nigeria will aid at combating media misrepresentation of nurses. This is a call to the NFVCB to be alive to their responsibilities in censorship, regulation and control of all cinematographic exhibitions in Nigeria (NFVCB, 2017). Similarly, censorship affords the removal of sensitive contents of a movie that promotes libel and slander, child pornography, and violence. Therefore, to describe the board of censors as a burdenbearing board; that fights against moral decadence and promotes national values through entertainment is not an overstatement.

However, it should be noted that the digitisation of the movie industry, characterised by migration from the use of Compact Disks (CDs) to the online method of marketing, which is also known as Onlinewood, has been a means of escaping the process of censorship (Adelakun, 2018). Hence, for thorough censorship of Nollywood movies to be fully incorporated and misrepresentation of nurses combated, the censor's board should intensify their efforts on the movies on $\mathrm{CD}$ and spread their censorial tentacles to movies released online. This no doubt is a call for change regarding the quality and standard of movies produced by Nollywood producers to prevent further perpetuation of misrepresentation of nurses and the nursing profession in the Nigerian health sector. 


\section{RECOMMENDATIONS AND CONCLUSION}

The misrepresentation of nurses in Nigerian Nollywood movies has negatively affected the public's view about the true image of nurses. This research paper tries to reposition nurses into their rightful and enviable position to prevent the true image of nurses and the public's perspective from drifting apart. It presented the effects that this menace may have on the reputation of the Nigerian nurses, some of which include loss of trust in the competency of healthcare workers, loss of occupational pride of nurses and loss of interest in choosing nursing as a career, amongst others. It also described the true image of nurses in relation to their functions.

Finally, the paper recommended some ways to rescue nurses and the nursing profession in Nigeria from the Nollywood thespians' misrepresentation. Prominent among the ways are proper censor of movies by the censor's board in Nigeria to remove derogatory contents from the movies; adequate research about the nursing profession by producers and actors; public campaign by nurses on their roles in healthcare and against production and distribution of such erroneous works. Others include: nurses should have the the right attitude to work and imbibe professional values in dispensing their duties. Likewise, nursing professional bodies in Nigeria should maintain their stance in protecting the profession and its members.

The paper, therefore, concludes on the note that, if all the aforementioned recommendations are strictly adhered to, nurses and the nursing profession will not only be freed from the menace of media misrepresentation, but will also thrive and compete favorably with their counterpart in foreign healthcare institutions.

\section{REFERENCES}

Adejumo, P.O. (2018). 'Riding through Risks into New Frontiers: The Nurse, The Nursed and Nursing.' The 452nd Inaugural Lecture Delivered at The University of Ibadan. Available at www.ui.edu.ng Accessed on 15th December 2020.

Adelakun, L.A. (2018). 'Nollywood to Onlinewood: Issues on Film Censorship and National Security in Nigeria'. In Journal of Social Sciences, 2(2); 193-230.

Ajah, K. (2018). 'I Am Not A Nollywood Stereotype; I Am A Nurse'. Available at www.nursingworldnigeria.com Accessed on 6th October 2020.

American Nurses Association (2020). 'What is Nursing and What do Nurses do'. Available at www.nursingworld.org .Accessed on 7th October 2020.

Cannon, D.\& Gardner, L. (2009). 'Character Building and what makes a Truly Great Actor'. Available at www.theguardian.com. Accessed on 9th December 2020.

Chikeme, P.C., Ogbonnaya, N.P., Anarado, A.N., Ihudiebube-Splendor, C.N., Madu, O. \& Israel, C.E., (2019).'Professional Values of Nigerian Nursing Students'.In International Journal of Medical Research and Health Sciences. 8(3): 26-35

Escobar, C.\&Heilemann, M.V. (2019). 'Reimagining Nursing on Screen: How Marvel's Claire Temple and BBC's Call the Midwife Get it Right'. The Online Journal of Issues in Nursing. 24 (1).

Guardian Newspapers (2019). 'The Nigerian Film Industry.Available at https://m.guardian.ng Accessed on 7th October, 2020. 
Henderson, V. (1966).'The Nature of Nursing: A Definition and its Implication for Practice, and Education.' 2nd Edition. Michigan: Macmillan.

ICM Definitions, (2018). Available at www.internationalmidwives.org. Accessed on $16^{\text {th }}$ February 2021.

Kubrak, T. (2020).'Impact of Films: Changes in Young People's Attitudes after Watching a Movie' .In Behavioral Sciences. 10(5):86.

Lai, P.K., \& Lim, P.H. (2012). 'Concept of Professional Socialization in Nursing'.In Int $E$ - $J$ Sci Med Edu, 6: 31-35.

Lailas News, (2020). 'Nigerian Nurses Attack Olamide over Wonma Music Video'. Available at www.lailasnews.com .Accessed on $27^{\text {th }}$ November 2020.

National Academy of Sciences, 2015. 'The Power of Television and Film'. Washington (DC): National Academies Press. Available at www.ncbi.nlm.nih.gov

National Film and Video Censors Board, (2017).Website available at www.nfvcb.gov.ng. Accessed on $30^{\text {th }}$ December 2020.

Nielson, A. (2012). 'Five Common Myths About the Nursing Profession. Available at www.nursingworldnigeria.com Accessed on 17th October 2020.

Nursing World Nigeria, (2012).'Nursing Council Visit to Nollywood Movie Producers'. Available at www.nursingworldnigeria.com. Accessed on 9th December, 2020.

Oyetunde, M.O. ,Kelechi, O.M. \&Oyediran, M.O. (2014). 'Perception of Patients and Other Health Care Professionals about Nurses at the University College Hospital, Ibadan, Oyo State, Nigeria'.In the Open Journal of Nursing, 4: 947-955.

Pairman, S. \& Tumilty, E. (2016).'International Confederation of Midwives Regulatory Toolkit'. A Technical Report (April 2016).

Poorchangizi, B., Farokhzadian, J., Abbaszadeh, A., Mirzaee, M., \&Borhani, F. (2017).'The Importance of Professional Values from Clinical Nurses' Perspective in Hospitals of a Medical University in Iran'. In BMC Medical Ethics, 18:20

Shahriari, M., Mohammadi, E., Abbaszadeh, A., \&Bahrami, M. (2013). 'Nursing Ethical Values and Definitions: A Literature Review'. In the Iranian Journal of Nursing and Midwifery Research, 18(1): 1-8.

Shetty, A.P. (2016). 'Florence Nightingale: The queen of nurses'. In Arch Med Health Sci.4: 144-148.

This Day, (2021). 'Nurses in Ondo Protest Assault on Colleagues'. Available at www.thisdaylive.com. Accessed on $16^{\text {th }}$ February 2021.

Ubochi. N.E., Ehwarieme, T.A., Anarado, A.N., \&Oyibocha, E.O. (2019). 'Building a Strong and Sustainable Health Care System in Nigeria: The Role of the Nurse'. In International Journal of Nursing and Midwifery. 11(7):61-67.

West, M., Wantz, D., Campbell, P., Rosler, G., Troutman, D., \&Muthler, C. (2016). 'Contributing to a Quality Patient Experience: Applying Evidence-Based Practice to Support Changes in Nursing Dress Code Policies. In The Online Journal of Issues in Nursing.21(1).

Wikipedia (2020). 'Virginia Henderson'. Available at https://en.m.wikipedia.org . Accessed on $15^{\text {th }}$ December, 2020.

Wocial, L.D., Sego, K., Rager, C., Laubersheimer, S., \& Everett, L.Q. (2014). 'Image is more than a Uniform'. In Journal of Nursing Administration.44(5): 298-302.

World Health Organization, (2010). 'Monitoring the Building Blocks of Health Systems: A Handbook of Indicators and their Measurement Strategies'. Geneva Switzerland: WHO Press. 